\title{
A MULTI-ATTRIBUTE DECISION MAKING MODEL FOR HOSPITAL LOCATION SELECTION
}

\begin{abstract}
Demand for the healthcare sector is increasing day by day because of facts such as population growth, increase in average human lifespan, changing eating habits and the rapid spread of epidemics in large areas. To meet the demand increase in the health sector and to reach high standards in the health sector, new hospitals are being established in Turkey. Therefore, the selection of hospital location arises as an important decision problem. In case of an inaccurate hospital location selection, besides a large monetary load, loss of human life may occur. For this reason, hospital location selection should be treated by analytical and rational methods. For this purpose, in this study, a hybrid Multi-Attribute Decision Making model in which importance of attributes are determined using Analytic Network Process(ANP) method and evaluation of alternatives is carried out using PROMETHEE method is proposed. As a case study, the proposed model is utilized to make a suitable location selection for a hospital in Trabzon province of Turkey.
\end{abstract}

Keywords: healthcare; hospital location; ANP; PROMETHEE.

\section{Introduction}

Diseases are rapidly increasing because of environmental factors brought about by modern life, changing eating habits, the increase in the rate of the elderly population. This leads to an increase in demand for the health sector and requires the construction of new hospitals. Hospitals are important components of health systems and the key points of the reforms in the health sector. Health spending is increasing both in Turkey and in other countries. For this reason, governments attach great importance to the more effective use of hospitals. Although the effectiveness of hospitals is affected by many factors, they can be grouped under two headings which are clinical effectiveness and managerial effectiveness. Hospital location selection is one of the key elements of managerial effectiveness. An appropriate selection of the location will attract a huge amount of potential patients, and it will affect the hospital's business success. On the other hand, an improper location selection for a hospital will result in the loss of human lives. Additionally, an incorrect location selection for a hospital will also create a large monetary load, likewise any location selection for any purpose. For these reasons, the hospital location selection should be focused on by analytical and rational methods. Multi-Attribute Decision Making (MADM) methods, which offer an integrated assessment that takes into account many factors and evaluates alternatives with respect to these factors, may be considered for the treatment of hospital location selection decision problems.

In this study, a hybrid MADM model in which priorities of attributes are determined using Analytic Network Process method and priorities of alternatives is identified using PROMETHEE method is proposed.

International Symposium on the Analytic Hierarchy Process
1

WEB CONFERENCE

DEC. 3 - DEC. 6,2020 


\section{Literature Review}

There are studies which offer an appropriate hospital location in a city. Şahin et al. (2019) have developed a hospital location selection model for Muğla province of Turkey by utilizing AHP. Aydın and Arslan (2010) have given the decision on which of the five candidate regions would be appropriate to establish a new hospital in Ankara by Fuzzy AHP. For the planned establishment of a new hospital in the 5th Region of Iran's Şiran town, Soltani and Marandi (2011) have set three alternatives by Fuzzy AHP and GIS and then determined the area to establish the hospital by fuzzy ANP. Kim et al. (2015) proposed a decision support system for hospital location selection in Dallas for the elder population by integrating AHP and GIS.

The features that distinguish this study from existing studies are a comprehensive consideration of the evaluation attributes; an integrated MADM approach utilizing ANP and PROMETHEE to consider the characteristics of different attributes for the evaluation of alternatives; treatment of a local decision problem for Trabzon Province of Turkey where there has been no hospital location selection application done before.

\section{Hypotheses/Objectives}

Trabzon, located in the Eastern Black Sea Region of Turkey, is at the beginning of the transit route between the Caucasus and Iran. In Trabzon, there are 22 hospitals. Trabzon is on its way to becoming the main health center of the region. In conjunction with increasing demand, there is still a shortage of hospitals in Trabzon. For this reason, in this study, we aim to find an appropriate location for a new hospital building in Trabzon.

\section{Research Design/Methodology}

Among 11 experts participated to our study, five of them were medical doctors (MDs) working in the county, another five were authorities working at Trabzon Provincial Health Directorate, and the last one was an authority working at Trabzon Regional Directorate of Transport and Infrastructure.

The counties of Trabzon province were considered as alternatives. To evaluate these counties, attributes were identified. For this purpose, a detailed literature review was conducted. After discussing the attributes in the literature with the experts participated to our study through Delphi technique, we came up with a final list of 14 attributes under 4 categories (see Appendix 1). As a further step, the existence of effects among attributes were identified using opinions of experts. Majority rule took place at this step. Because of dependencies and feedbacks, we utilized the ANP method and requested the experts to response pairwise comparison questions to reveal the importance of the attributes. We computed the geometric averages of the responses. Super Decisions software revealed the priorities of attributes according to MDs, civil authorities, and the whole group of experts. At the next step, alternatives were rated with respect to attributes to construct a decision matrix. For the subjective attributes, experts' opinions were assessed on a 0-100 scale and then arithmetic averages of the responses were computed. For the objective attributes, on the other hand, relevant sources such as Turkish Statistical Institute, Public Health Agency of Turkey, Trabzon Provincial Public Health Office, Republic of Turkey General Directorate of Highways were used.

Following this step, we used Visual PROMETHEE program to rank the counties that can be appropriate to establish the hospital. The reason of using the PROMETHEE method in this study is that the method enables the characteristics of the attributes, to be transferred

International Symposium on the Analytic Hierarchy Process
WEB CONFERENCE

DEC. 3 - DEC. 6,2020 
to the model in a better way, with the opportunity of experts to determine different preference functions for attributes.

At the final step, we conducted sensitivity analysis.

\section{Data/Model Analysis}

The decision network developed is given in Figure 1. The revealed priorities of the attributes are given in Appendix 2. The ranking of alternatives is given in Appendix 3. Sensitivity analysis results are not shown due to indicated page limit constraint.

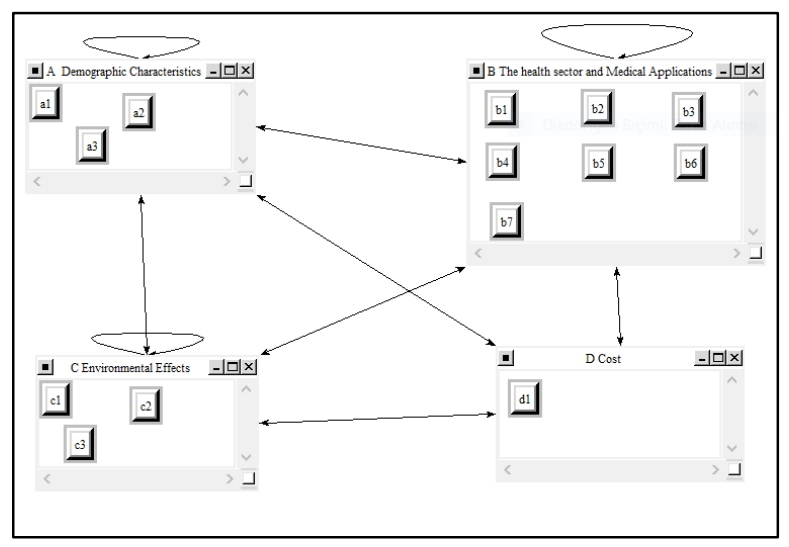

Figure 1. The ANP model

\section{Limitations}

The number of participants in two groups (i.e. medical doctors and civil authorities) may be increased. Besides, the opinions of the residents of the city may be assessed.

\section{Conclusions}

We presented the priorities of the attributes and alternatives and sensitivity analysis results to the authorities at Trabzon Provincial Health Directorate. Akçaabat county is determined as the most preferred hospital location. The population of the county, the centrality of the location, and the number of private hospitals at the county are the most important factors. The authors are planning to contact with more medical doctors and civil authorities, and then to conduct a survey to discover the preferences of the residents living in Trabzon by utilizing the proposed approach.

\section{Key References}

Aydin, O., \& Arslan, G. (2010). Optimal hospital location with fuzzy AHP. The Business Review, Cambridge, 15, 262-268.

Kim, J. I., Senaratna, D. M., Ruza, J., Kam, C., and Ng, S. (2015). Feasibility study on an evidence-based decision-support system for hospital site selection for an aging population. Sustainability, 7(3), 2730-2744.

Sahin, T., Ocak, S., \& Top, M. (2019). Analytic hierarchy process for hospital site selection. Health Policy and Technology, 8(1), 42-50. 
Soltani, A., \& Marandi, E. Z. (2011). Hospital site selection using two-stage fuzzy multicriteria decision making process. Journal of Urban and Environmental Engineering, 5(1), $32-43$.

\section{Appendices}

Appendix 1. The Attributes of the Decision Model

\begin{tabular}{ll}
\hline $\begin{array}{l}\text { Attribute } \\
\text { categories }\end{array}$ & Attributes \\
\hline $\begin{array}{l}\text { A. Demographic } \\
\text { Characteristics }\end{array}$ & $\begin{array}{l}\text { A1.Population } \\
\text { A2.Population density } \\
\text { A3. Centrality }\end{array}$ \\
\hline & B1. The number of family health centres (FHCs) in the county \\
& B2. The number of physicians in the FHCs \\
B. The health & B3. The number of public hospitals (PHs) in the county \\
sector and medical & B4. Total number of beds in the county's PHs \\
applications & B5. The number of branch hospitals (BHs) in the county \\
& B6. Total number of beds in the county's BHs \\
& B7. The number of PHs in the county. \\
\hline C. Environmental & C1. Distance to the main roads \\
effects & C2. Traffic congestion \\
\hline D. Cost & D1. Noise centre \\
\hline
\end{tabular}

Appendix 2. The Priorities of the Attributes

\begin{tabular}{llccc}
\hline Attribute & $\begin{array}{c}\text { Priorities } \\
\text { according } \\
\text { to MD }\end{array}$ & $\begin{array}{c}\text { Priorities } \\
\text { according } \\
\text { to civil } \\
\text { authorities }\end{array}$ & $\begin{array}{c}\text { Overall } \\
\text { priorities }\end{array}$ \\
\hline A & A1. Population & 0.2909 & 0.2898 & 0.2891 \\
& A3. Centrality & 0.1856 & 0.1700 & 0.1780 \\
A2. Population density & 0.0208 & 0.0409 & 0.0318 \\
\hline & B3. Number of PHs & 0.1160 & 0.1246 & 0.1198 \\
& B5. Number of BHs & 0.0469 & 0.0505 & 0.0496 \\
& B4. Total number of beds in the PHs & 0.0235 & 0.0346 & 0.0305 \\
B & 0.0316 & 0.0143 & 0.0203 \\
& B1. Number of FHCs & 0.0179 & 0.0172 & 0.0180 \\
& B7. Number of PHs & 0.0128 & 0.0137 & 0.0135 \\
& B6. Number of beds in the BHs & 0.0103 & 0.0085 & 0.0095 \\
\hline B2. Number of physicians in FHCs & C1. Distance to main roads & 0.1121 & 0.1101 & 0.1114 \\
C & C2. Traffic congestion & 0.0594 & 0.0599 & 0.0598 \\
& C3. Noise center & 0.0148 & 0.0090 & 0.0112 \\
\hline D $\quad$ D1. Land cost & 0.0574 & 0.0570 & 0.0572 \\
\hline
\end{tabular}


International Symposium on the Analytic Hierarchy Process 2020, Web Conference.

Appendix 3. The complete pre-order obtained by PROMETHEE II

\begin{tabular}{|c|c|c|c|c|c|}
\hline \multicolumn{3}{|c|}{ PROMETHEE Flow Table } & \multicolumn{3}{|c|}{$\begin{array}{llll} & 0 & \text { 回 } & x \\
\end{array}$} \\
\hline Rank & action & & Phi & Phit & Phi- \\
\hline 1 & Akçaabat & $\square$ & 0,1892 & 0,3302 & 0,1410 \\
\hline 2 & Ortahisar & & 0,1503 & 0,5082 & 0,3579 \\
\hline 3 & of & & 0,0725 & 0,1360 & 0,0636 \\
\hline 4 & Arakı & & 0,0636 & 0,1393 & 0,0757 \\
\hline 5 & Beşikdüzü & & 0,0577 & 0,1137 & 0,0560 \\
\hline 6 & Çarşıbaşı & $\square$ & 0,0518 & 0,1098 & 0,0580 \\
\hline 7 & Arsin & $\square$ & 0,0473 & 0,1180 & 0,0707 \\
\hline 8 & Vakfikebir & 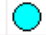 & 0,0404 & 0,1152 & 0,0748 \\
\hline 9 & Hayrat & & $-0,0066$ & 0,1228 & 0,1294 \\
\hline 10 & Sürmene & 0 & $-0,0083$ & 0,0886 & 0,0969 \\
\hline 11 & Yomra & $<$ & $-0,0250$ & 0,1100 & 0,1350 \\
\hline 12 & Şalpazarı & 0 & $-0,0353$ & 0,0861 & 0,1214 \\
\hline 13 & Dernekpazarı & $\square$ & $-0,0510$ & 0,1012 & 0,1523 \\
\hline 14 & Mackka & 0 & $-0,0791$ & 0,0893 & 0,1683 \\
\hline 15 & Tonya & 0 & $-0,0949$ & 0,0564 & 0,1514 \\
\hline 16 & Köprübaşı & 0 & $-0,1018$ & 0,0643 & 0,1661 \\
\hline 17 & Düzköy & $\square$ & $-0,1117$ & 0,0532 & 0,1648 \\
\hline 18 & Çaykara & $\square$ & $-0,1588$ & 0,0401 & 0,1989 \\
\hline
\end{tabular}

